\title{
The location of descending fibres to sympathetic preganglionic vasomotor and sudomotor neurons in
}

\section{man}

\author{
P W NATHAN, ${ }^{*}$ MARION C SMITH*† \\ From the National Hospital for Nervous Diseases, ${ }^{*}$ Queen Square, London and the Radcliffe Infirmary, $\dagger$ \\ Oxford, UK
}

SUMMARY Evidence is given of the location in the spinal cord of man of the central sympathetic fibres supplying vasomotor and sudomotor neurons of the body caudal to the head and neck. The evidence is based on anterolateral cordotomies. The fibres lie within the medial part of the equatorial plane, extending from the base of the posterior horn and the lateral horn across the medial half of the white matter. The evidence from a previous paper together with that of the present paper is that the pathway maintains this position throughout the spinal cord as far as the L 2 segment. The sympathomotor fibres caudal to the head and neck are supplied from both sides of the cord: sympathetic activity is not removed, although it may be slightly diminished, by a hemisection of the cord. The evidence suggests that sympathetic fibres for vasomotor control leave the cord cranial to the Th 7 segment. The knowledge of the location of the pathways is of value to neurosurgeons so that they may be avoided in the operation of anterolateral cordotomy.

We have previously presented evidence of the course in man of the central sympathetic fibres that supply the neurons innervating the orbit and the sweat glands of the head and neck. ${ }^{1}$ In the present paper, we present evidence on the further course of the fibres to the sympathetic preganglionic cell groups that supply vasomotor and sudomotor neurons to the rest of the body. From species other than man, we know that there are several parallel pathways, some excitatory, some inhibitory, which take origin in the hypothalamus, pons and medulla. Some of these fibres run directly, others relay in their course. The fibres that run to the intermediomedial and intermediolateral nuclei of the spinal cord, in the cat and the rat, take origin in the following nuclei: the paraventricular and parafascicular nuclei of the hypothalamus, the dorsal and medial periaqueductal gray of the midbrain, the pontine tegmentum, the locus coeruleus, the ventral part of the raphe nuclei, the nuclei of both tracti solitarii, cells surrounding the superior olive, the

Address for reprint requests: PW Nathan, The National Hospital for Nervous Diseases, Queen Square, London WCIN 3BG, UK.

Received 16 December 1986.

Accepted 11 February 1987 nucleus paragigantocellularis lateralis (Olszewski and Baxter ${ }^{2}$ ) and the nucleus subretrofacialis. The latter group of neurons is also known as $\mathrm{CI}$. They give rise to myelinated and non-myelinated fibres in the rat. Their function is cardiovascular; division of the fibres bilaterally reduces the blood pressure to nil.

In this paper we mainly refer to the literature on man and the monkey. Foerster ${ }^{3}$ and Foerster et $\mathrm{al}^{4}$ located the spinal course of these descending tracts for tonic vasoconstriction and for sweating on the evidence obtained from Foerster's anterolateral cordotomies. Eight of his cases had post mortem examinations. Foerster and his colleagues were the first investigators in this field, and their evidence established that these tracts were likely to be divided in cordotomies.

Guttmann ${ }^{5}$ stated in his book on spinal injuries that "the supranuclear sudomotor fibres pass through the posterior aspect of the anterolateral tract very close to the lateral pyramidal tract and the border zone of the intermedio-lateral horns". Probably his evidence came from Foerster's cordotomies. The classical and rather neglected papers by Laruelle ${ }^{67}$ on many species including man emphasise that the sympathetic centres within the gray matter consist of cellulo-fibrillary columns. He showed histologically that there were two columns, an intermedio-medial 
and an intermedio-lateral. Of these, the intermediolateral column contains the greater number of neurons and also of connecting fibres.

Important experimental work on the location of the descending fibres in cats and monkeys was carried out by Kerr and Alexander: ${ }^{8}$ the results were essentially the same in two species. They stimulated both the surface and depth of the cord, confirming the point of stimulation post mortem in serial sections. They recorded blood pressure and pilomotor responses. In the monkey, at Th 2 segment, slight vasopressor responses were obtained from stimulation of the lateral corticospinal tract and the region between this tract and the gray matter and marked responses were obtained from stimulation just within the lateral horn. In the cat, stimulation of the surface of the lateral part of the cord produced a vasopressor response, and bilateral section of the region removed the response. They found that stimulation of both the intermedio-lateral nucleus of the gray matter and of the superficial region of the lateral column of the white matter produced the vasopressor response, but as cutting the lateral part of the white matter stopped the response they concluded that the intermediate deep part of the white matter, occupied by lateral reticulospinal fibres, did not convey descending fibres causing vasoconstriction.

Illert and Gabriel $^{9}$ mapped descending fibres with an inhibitory effect on sympathetic function in the cat. These fibres were found to be scattered throughout a large part of the lateral column. They were scarce in the anterior and posterolateral columns, most of them being "in the ventrolateral column in the region between the midline and the dentate ligament".

Descending excitatory fibres were located in the cord of the cat on the surface of the lateral column in the upper three thoracic segments by Foreman and Wurster. ${ }^{10}$ Although they stimulated only between the dorsolateral sulcus and the dentate ligament, the significance of the region was confirmed by lesions "made on the surface of the dorsolateral funiculi". They were mainly concerned with vasopressor activity; but as they recorded from the white rami communicantes, they were obtaining evidence for all preganglionic fibres. "Unilateral and bilateral lesions made on the surface of the dorsolateral funiculi" caused decreases in the blood pressure. In the dog, Barman and Wurster ${ }^{11}$ also concluded from stimulation of the cord between $\mathrm{C} 3$ and $\mathrm{C} 5$ segments that the tract for vasopressor control was on the dorsolateral surface of the cord. They considered that changes induced by stimulation at deeper or neighbouring regions might be due to current spread, though they thought that this was unlikely. Saper et $a l^{12}$ investigated direct hypothalamo-autonomic connections in the rat, cat and monkey by horseradish peroxidase (HRP). The direct tract from the hypothalamus to the sympathomotor region of the thoracic cord ran "along the ventrolateral surface of the medulla". In the spinal cord the fibres were found to be scattered in the equatorial region of the lateral column.

In the cat, Kuypers and Maisky ${ }^{13}$ concluded from HRP studies that the hypothalamo-spinal fibres were "mainly in the lateral funiculus" though some were in the ventral funiculus. In their diagram these fibres are shown as being located within a narrow band near the periphery of all the anterior column and of the lateral column except the most posterior part.

\section{Patients}

The material consists of 88 cases of anterolateral cordotomy, the majority with post mortem verification. Of the histologically confirmed cases, 32 were used for determining the vasomotor pathway and 31 for the sudomotor pathway. In addition, some supporting evidence has been obtained from 27 unilateral cordotomies without post mortem examination.

\section{Methods}

Clinical Vasomotor The evidence of division of fibres for tonic vasomotor control was a fall in blood pressure during the cordotomy, and/or hypotension when the patient was under intensive care immediately after the operation, and/or fainting or almost fainting with low blood pressure when the patient got up after the operation.

Clinical Sudomotor The evidence of division of the sudomotor pathway was based on sweat tests, which were performed before and after the operation. The patient was given one pint of hot tea or coffee. The parts of the body not being examined for sweating were covered with heat cradles. The part being examined was sprinkled with quinizarin compound. ${ }^{14}$ Drawings and photographs were made. The postoperative tests were usually carried out between 2 and 4 weeks after the operation.

Histological Blocks of the cord were embedded in celloidin. Transverse sections were prepared by a variety of methods, including Weigert Pal, Loyez, phosphotungstic acid haematoxylin, Marchi, Glees, Erikson and Marsland, Gros Bielschowsky and Starega's ${ }^{15}$ modification of the Gros Bielschowsky method.

\section{Results}

DESCENDING FIBRES TO VASOMOTOR NEURONS (A) Unilateral cases During the operation of anterolateral cordotomy, a fall in blood pressure never occurred after an incision in the cord had been made unilaterally; and equally, during a bilateral operation, it did not occur after one side of the cord had been incised. In none of the 43 cases of unilateral cordotomy was there evidence of a marked fall in blood pressure with changes to the upright posture 
following the operation. This was so in the 16 cases in which the lesion was verified post mortem and the 27 cases without post mortem examination. These operations were done at all levels between the $\mathrm{C} 1$ and the L 2 segments. It is concluded that the vasoconstrictor neurons for the body below the head and neck are supplied from both sides of the cord. It is also concluded that in any case of bilateral cordotomy in which there is orthostatic hypotension, the descending tract must have been divided bilaterally; if there is no hypotension, then either one or both of the descending tracts is intact.

(B) Bilateral cases There were four cases with bilateral lesions in the upper thoracic cord in which vasomotor control was intact and so it can be concluded that the pathway was not divided on one or both sides of the cord. The lesions in these cases are shown in fig 1 . The regions that have not been divided are the most posterior part of the posterolateral column and a region extending from the base of the posterior horn and lateral horn posterolaterally to the periphery. The central part of this region was intact bilaterally.

There were six cases with lesions in the upper thoracic cord in which the pathway was divided bilaterally; they are shown in fig $2 a$ and $b$. They are all very large lesions. In two of the cases neither of the anterior columns was divided. Thus these cases shown that the descending fibres do not run in the anterior columns. In Case 92 on both sides and in Case 93 on the left side, the posterolateral column was at least partially intact; and there was vasomotor paralysis. These cases rule out the posterolateral sector as the location of the descending fibres. The lesions on the

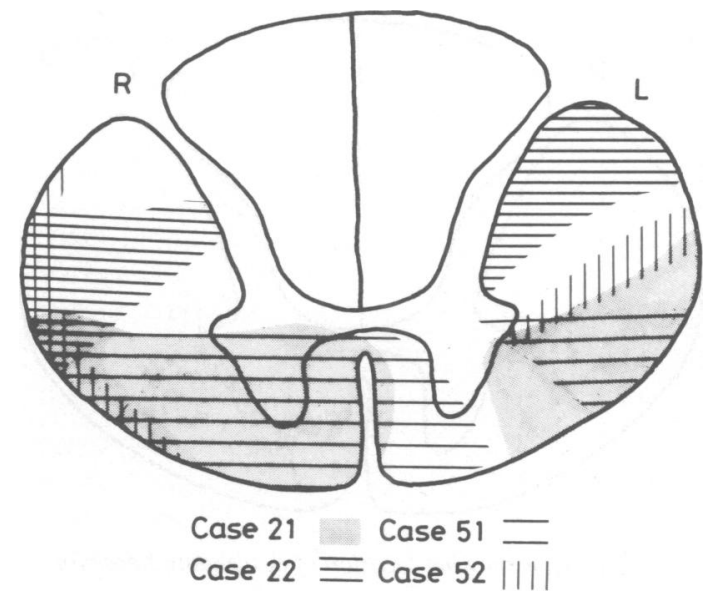

Fig 1 Vasomotor control normal: descending fibres not divided bilaterally. The intact regions are left unshaded. Cases 21, 22, 51, 52 .

left side of Cases 92, 77 and 10 all extend to the anterior and medial part of the region in the equatorial plane of the cord left unshaded in fig 1 . These three cases show that lesions dividing the anterior and the medial part of this area divide the descending fibres. The area, shown in fig 3 , is in the medial part of the equatorial plane; it extends from the base of the posterior horn and lateral horn across the medial third of the white matter of the lateral column. Owing to the nature of the cordotomy lesion, the gray matter of the lateral horn is sometimes included in the lesion. It is

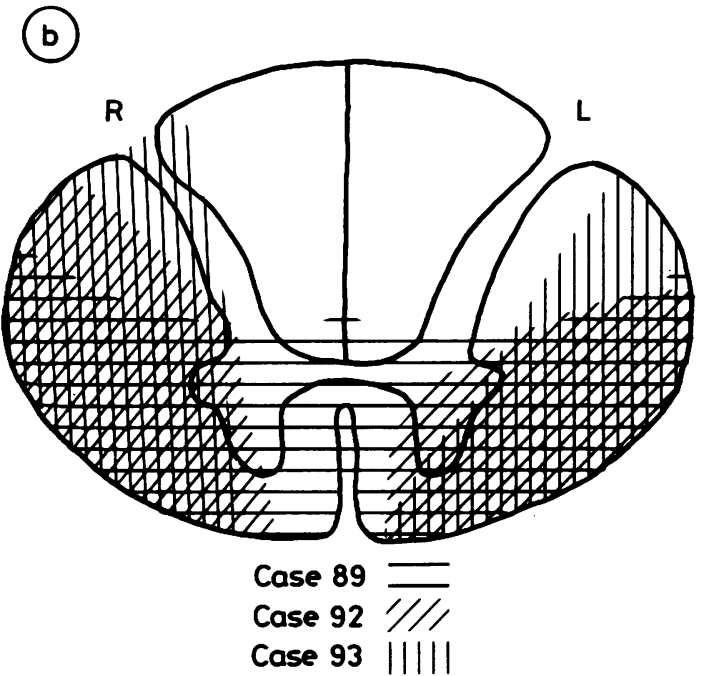

Fig 2 Vasomotor control absent: descending fibres divided bilaterally. (a) Cases 10, 34, 77 (b) Cases 89, 92, 93. 


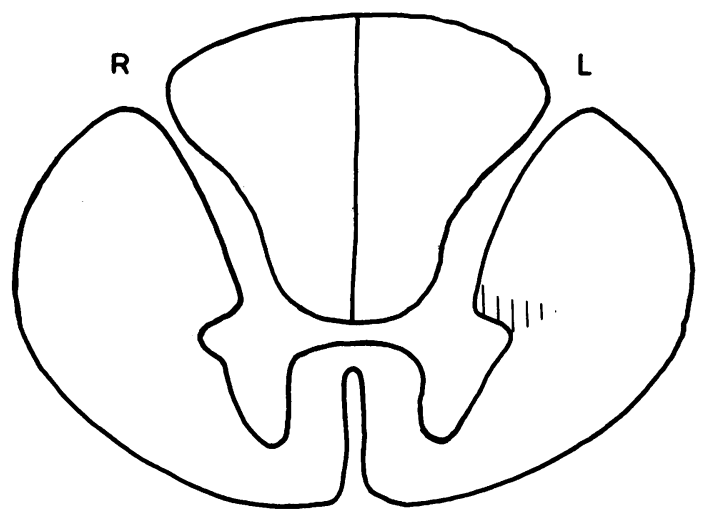

Fig 3 Diagram showing location of descending fibres for vasomotor control.

possible that this central part of the lesion also contributed to division of central descending sympathetic fibres.

(C) Involvement of the pathway in unilateral lesions The location of the descending fibres having been deduced, unilateral cordotomies were examined to see if this region was involved. In 12, it was involved, though in three only partially; in four it was not involved. In none of these 16 patients was there vasomotor paralysis. Thus these cases confirm that the pathway is bilateral.

(D) Bilateral low thoracic lesions without vasomotor disturbance There were eight bilateral cordotomies in which the operation was done below the Th 7 segment, with post mortem examination. In two of these, both of the incisions would not have involved the region of the descending tract, assuming that it remains in the same location in the lower thoracic segments. In the other six both incisions would have involved the tract. Yet in these cases, there was no vasomotor disturbance. This evidence indicates that the sympathetic rami concerned with vasomotor control of the viscera and lower part of the body leave the cord cranial to the Th 7 segment.

DESCENDING FIBRES TO SUDOMOTOR NEURONS (A) Effects of unilateral lesions (a) Cervical Cord: In Case 80, there was no disturbance of sweating below the neck. The large lesion at $\mathrm{C} 2$, shown in fig 4 , involved almost all of the anterolateral and lateral columns. (Histological sections of the oblique lesion in this case are shown in fig 9 of our previous paper.) As this very extensive unilateral lesion did not disturb sweating on either side of the body, it is concluded that the pathway for sudomotor activity below the head and neck runs bilaterally. Further evidence

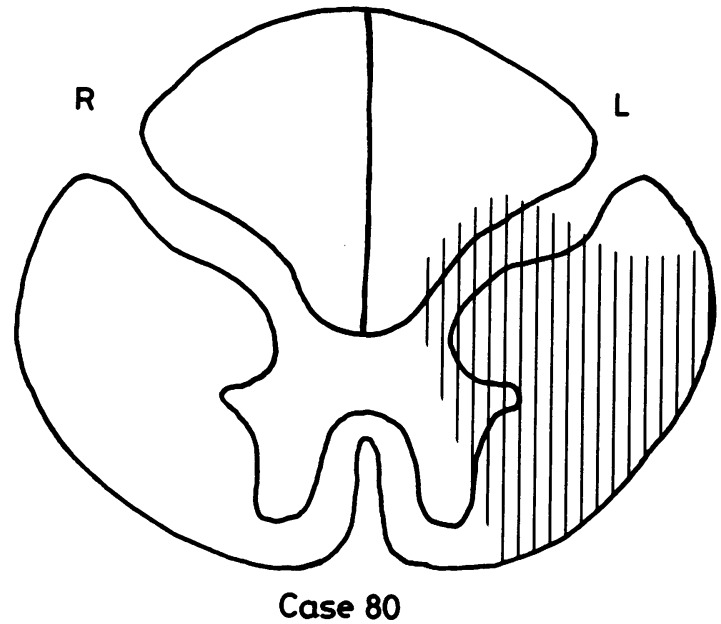

Fig 4 Sweating normal. Lesion in Case 80.

comes from seven unilateral cervical cordotomies with post mortem examination and two without: in none of these cases was there any disturbance of sweating below the head and neck. In two, there was a complete, and in one, a partial, Horner's syndrome; and in three there was anhidrosis and in one hypohidrosis of the face and neck.

(b) Thoracic cord: The table shows the effects on sweating of a unilateral thoracic cordotomy. In six of the 10 patients, post mortem confirmation was obtained. Sweating was unaffected by the operation in eight of the patients. In two without post mortem examination, there was some diminution of sweating on the side of the lesion. Although division of one descending tract may occasionally have some effect on sudomotor activity unilaterally, the evidence from the total 20 cases, 10 cervical and 10 thoracic, shows

Table 1 Unilateral cordotomy: sudomotor activity caudal to surgical lesion

\begin{tabular}{lcc}
\hline & $\begin{array}{l}\text { Level of } \\
\text { lesion }\end{array}$ & $\begin{array}{l}\text { Sweating equal } \\
\text { bilaterally }\end{array}$ \\
\hline Case numbers & Patients with necropsy & examination \\
93 & Th 3 & Yes \\
81 & Th 3-4 & Yes \\
71 & Th 5 & Yes \\
61 & Th 5 & Yes \\
32 & Th 7 & Yes \\
38 & Th 9 & Yes \\
& & \\
Ste & Patients without necropsy examination \\
Mar & Th 1 & Yes \\
Cor & Th 2 & Diminished ipsilaterally \\
Pin & Th 2 & Diminished ipsilaterally \\
\hline
\end{tabular}



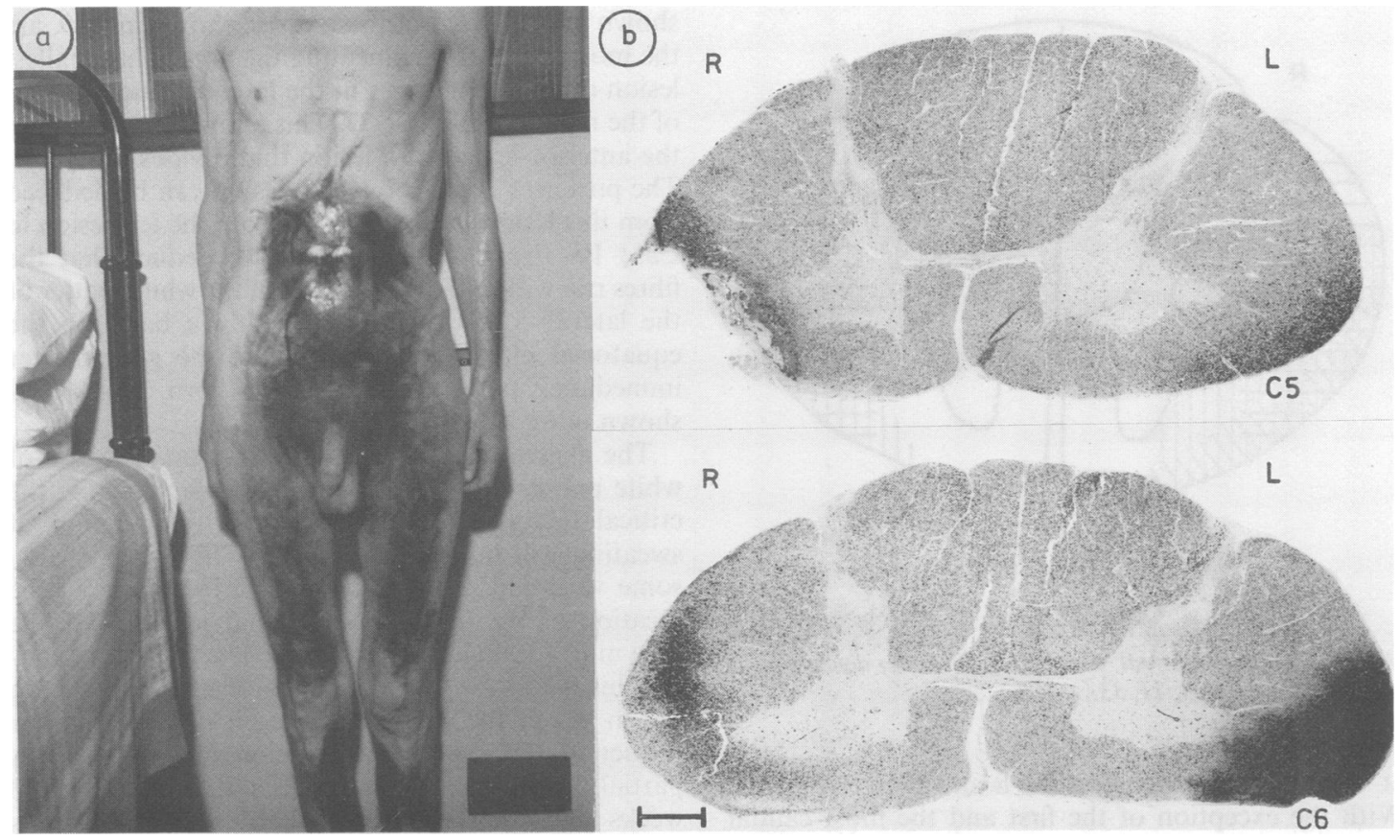

Fig 5 (a) Normal sweating on abdomen and legs. The patient has a suprapubic cystostomy. (b) Lesions at C 5-6 segments. Marchi preparations. Bar $=1 \mathrm{~mm}$.

that the descending pathway of each side of the cord supplies the sudomotor neurons bilaterally.

(B) Location of the fibres in the lower cervical cord There was one case with a bilateral cordotomy carried out in the cervical cord, at the C 5-6 segments. The sweat test performed 1 month after the operation showed that sweating was normal in the area examined on the anterior surface of the body from the Th 8 dermatome caudally. The sweat test and the cordotomy lesions are shown in fig 5 . The evidence from this case indicates that the descending fibres do not run in the peripheral parts of the lateral column.

(C) Location of the fibres in the thoracic cord Before determining the location of the fibres in their further course in the white matter in the thoracic segments, it is necessary to consider whether there is conduction cranio-caudally within the gray matter. This question should be asked as there are cellulo-fibrillary sympathetic networks in the intermediate part of the gray matter and mainly in the lateral horn. ${ }^{6} 7$

The following cases provide evidence that extensive lesions of the white matter with sparing of much of the relevant parts of the gray matter on one or both sides interrupted sweating. The lesions are shown in fig 6. It is concluded that the gray matter alone does not contain descending fibres sufficient to maintain sweating.

In determining the course of the fibres in the white matter of the thoracic cord, we are considering lesions

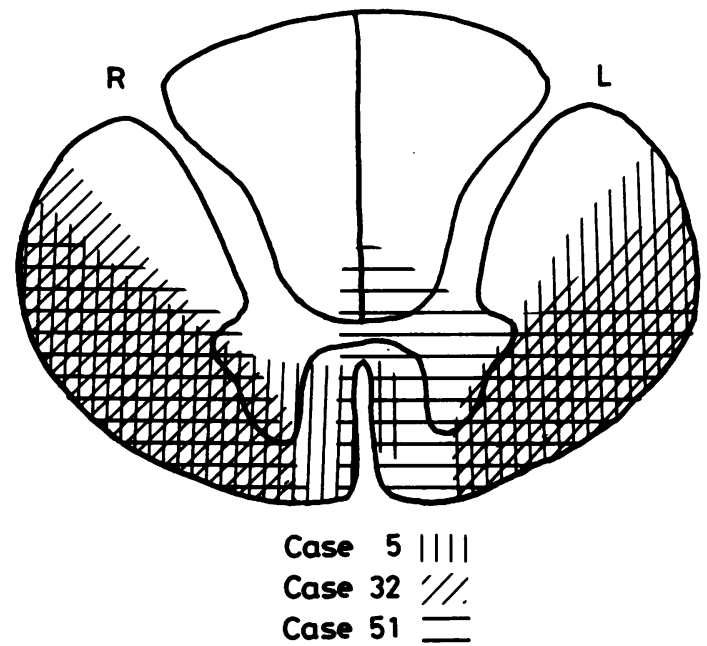

Fig 6 Sweating absent. Cases 5, 32, 51 . 


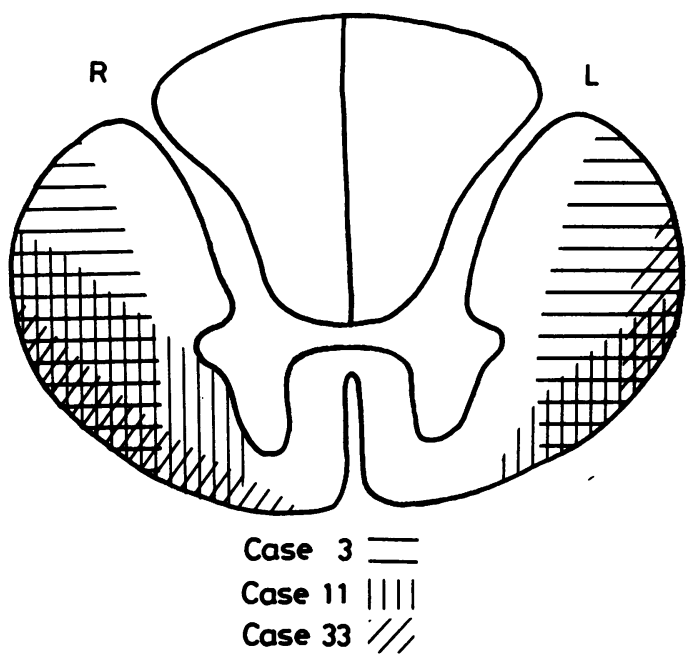

Fig 7 Sweating normal: descending fibres not divided bilaterally. Cases 3, 11, 33.

at various levels between Th 1 and Th 9 segments. With the exception of the first and the most caudal segments, the anatomical relationships remain fairly constant throughout the thoracic cord; and so the location of the descending fibres is most likely to remain the same at all levels. The cases shown first are those in which the lesions did not interrupt sweating; they show the intact regions of the white matter within which the fibres or most of the fibres run. Secondly, cases are presented in which sweating was interrupted. In the first group are shown the intact regions of the white matter in which the fibres do not run; in the second group are shown the regions where the lesions did divide the descending fibres.

In the three cases shown in fig 7, sweating was not interrupted. The area that is not transected by any of the lesions on both sides is the medial zone of white matter. These three cases rule out a location of the descending fibres in the lateral two-thirds of the cord.

In the great majority of our cases, the white matter of the posterior half of the region was not included in the lesions; and sweating was interrupted. Thus, the descending fibres do not run in this region, lateral to the posterior horn.

In fig 8 are shown the lesions in which the anterior columns are intact or minimally involved, at least on one side. In all of these cases, sweating was absent. Thus they show that the descending sympathetic fibres do not run in the anterior columns. There were nine cases in which the region lateral to the anterior and lateral horns was divided bilaterally. In three, the lesions were too large to be useful in deducing the area within which the fibres lie. The other six cases are shown in fig 8 . Two of these cases, shown in fig 9, are the most useful for delineating the area. The smallest lesion dividing the fibres in the lateral column is that of the right side of Case 77. This allows one to deduce the anterior extent of a lesion that divides the fibres. The posterior extent of such a lesion can be deduced from this lesion in Case 77 and from the left lesion in Case 10. From these six cases we deduce that the fibres run within the medial half of the white matter of the lateral column; they are within a band on the equatorial plane, abutting against the gray matter immediately posterior to the lateral horn. This area is shown in fig 10.

The degree of involvement of this small region of white matter in the equatorial plane is probably the critical factor in deciding whether interruption of sweating will be total or partial. There is probably some variation in the antero-posterior extent of the location of the fibres. Lesions that just include the area may not divide all the fibres. The reason for stating this is that we have one other case (Case 21) (fig 11 ) in which the lesions just reach to the posterior border of the region; interruption of sweating was partial. In this patient, sweat tests were carried out 3 weeks and 3 months after the cordotomy; the results were the same in the two tests. The lesions were in the Th 1-2 segments. Caudal to the Th 7 dermatome there was absence of sweating on the left and decreased sweating on the right. It must be concluded that the lesions, shown in fig 11, divided most but not all of the fibres.

(D) Cranial level of absence of sweating The cranial level of anhidrosis is some segments caudal to the spinal segment incised. This is due to the fact that the preganglionic sudomotor fibres issuing from the lateral horn synapse in the ganglia at more than one segmental level and the post-ganglionic fibres descend and ascend in the chain before leaving it in the gray rami. It is of some interest to record that when we first observed the differences in level between the incision in the cord and the level of anhidrosis many years ago, we asked Guttmann for his experience with total lesions of the spinal cord. He wrote to us: ${ }^{16}$ "In a complete lesion of the upper part of the thoracic cord, including the 6th dorsal segment, sweating occurs not further down than the 10th or 11th dermatome, as far as my own experience is concerned. I also found no sweating in the legs in complete lesions at the Th 7-8. This means that, although the individual spinal segments in that area show great overlap, their maximal function, as far as sweating is concerned, does not extend to the legs." For example, in Case 51 in which the cordotomy incisions were at the Th 5 segment, there was sweating on the abdomen above the pubis, minimal sweating in both groins (Th 12 dermatome) and no sweating below that. 


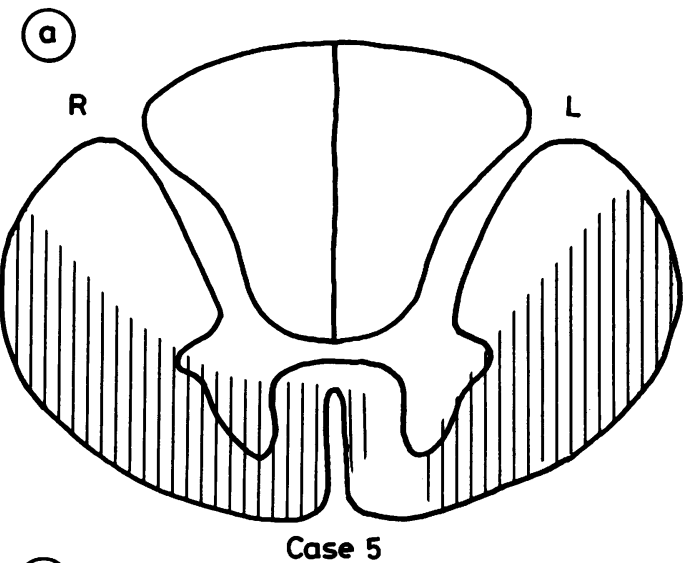

(c)

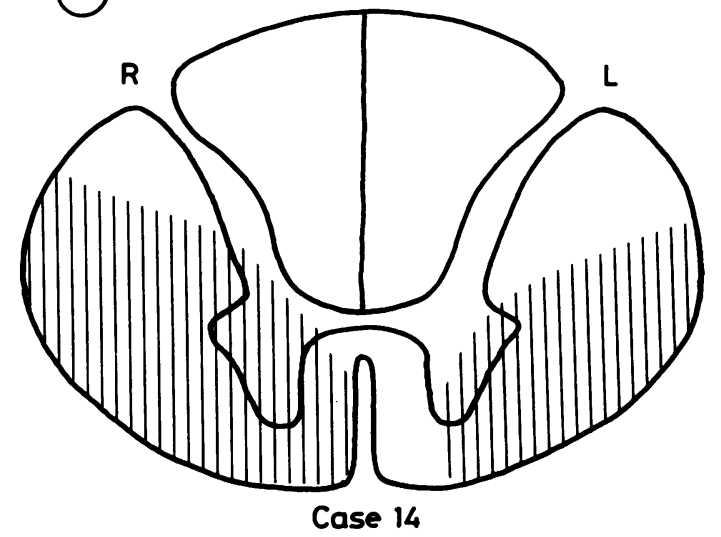

(e)

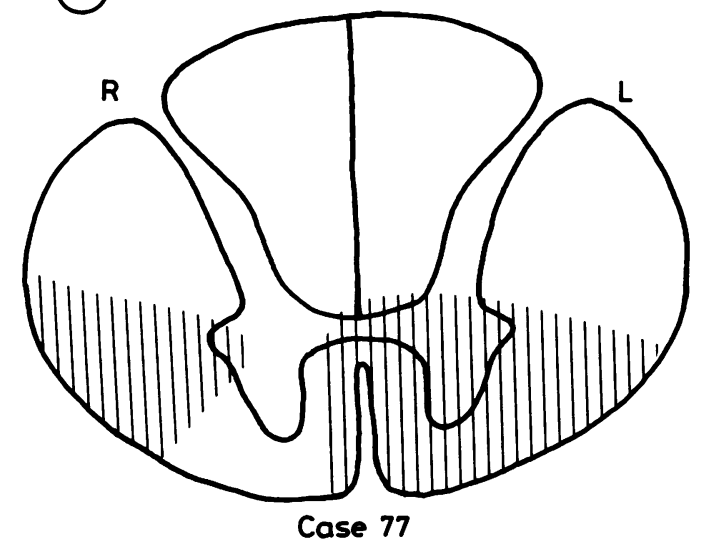

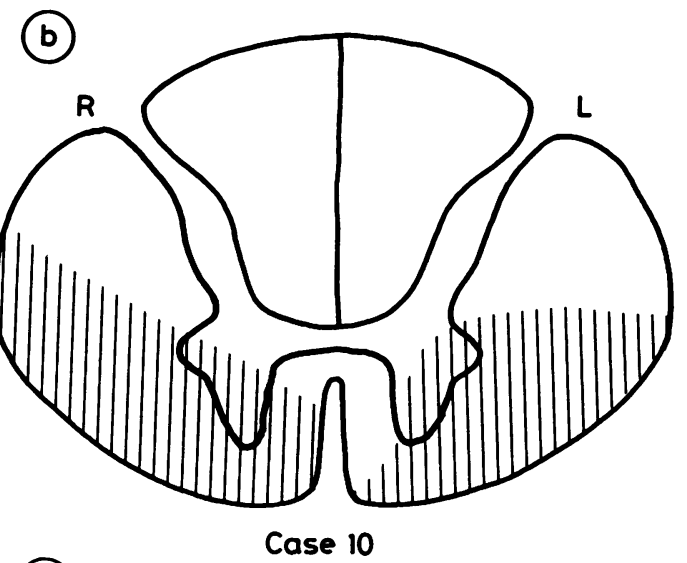

(d)

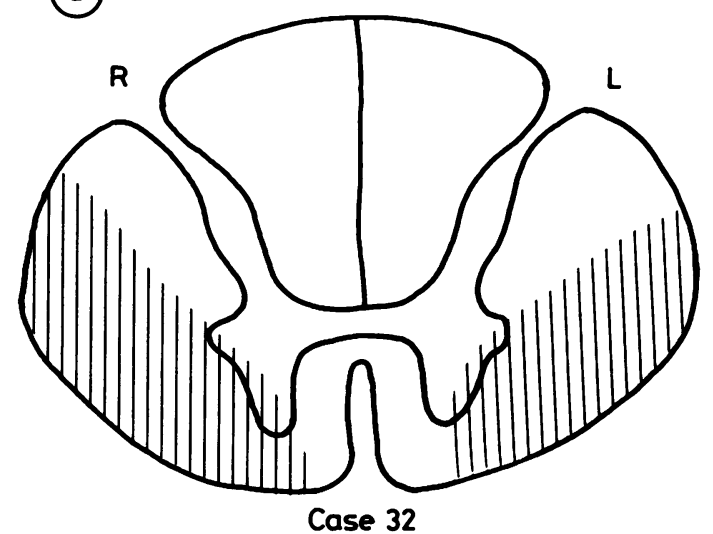

(f)

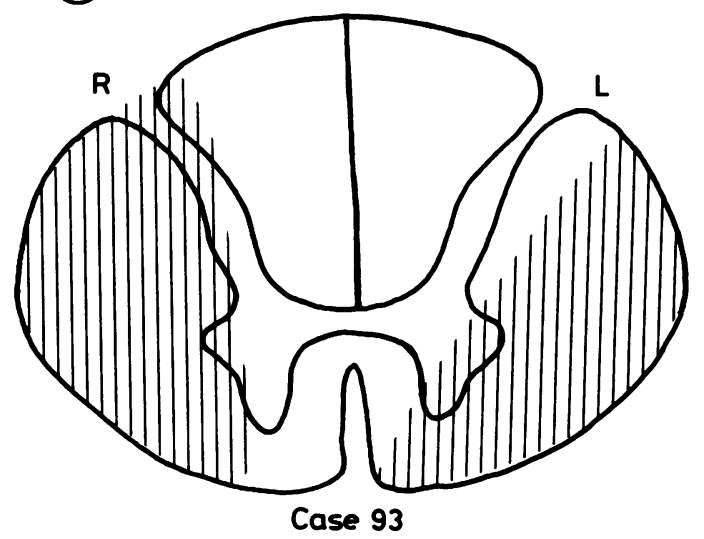

Fig 8 Sweating absent: descending fibres divided bilaterally. Cases 5, 10, 14, 32, 77, 93. 


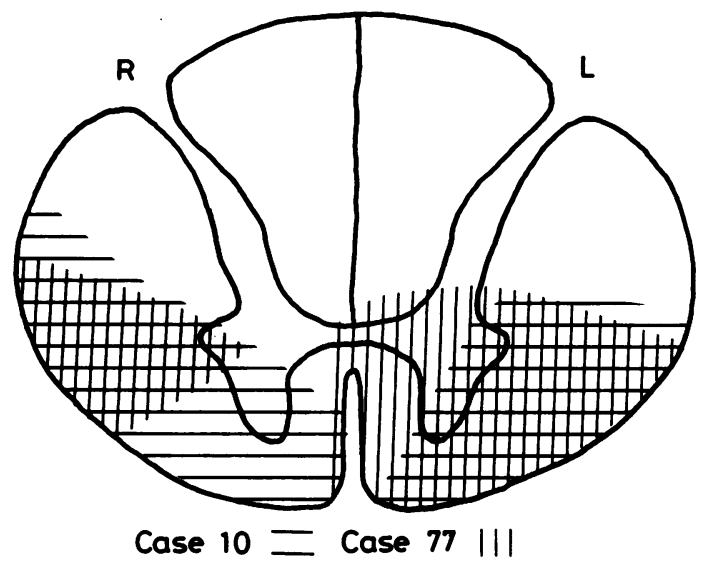

Fig 9 Sweating absent: descending fibres divided bilaterally. Lesions of Cases 10 and 77 superimposed.

In Case 63 in which the minsions were at the Th 8-9 segments, the quinizarin powder was scattered on the patient, lying on his abdomen, from his waist downwards. There was no sweating below the waist. Thus in this case, no sudomotor fibres descended from above Th 8-9 segments to supply the Th 10 dermatome or below. The lowest level at which a bilateral cordotomy with sweat tests was carried out was Case 49. Sweating was present on the lower limbs, though perhaps slightly diminished on the soles. In this case, the lesions of which are shown in fig 12, the axons of the sudomotor neurons for the lower limbs must have left the cord above the L 1-2 segments.

\section{Discussion}

Foerster and his colleagues ${ }^{34}$ were the first to use the material of anterolateral cordotomies to study the location of the descending fibres. They concluded that as the fibres were divided in cordotomies, they must run in the anterolateral and anterior columns. In a diagram, Foerster drew the "vascoconstrictor tract" in a boomerang shape immediately anterior to the lateral corticospinal tract, running from the dentate ligament to the lateral border of the anterior horn, hugging this border and then passing posteriorly along the lateral horn. It is difficult to see what evidence he had for the details of this location, even though in our opinion it is essentially correct! He found diminished sweating in unilateral cordotomies on the side of the lesion and never anhidrosis. Regarding the pathway for sweating, he said that they had insufficient evidence for the lower thoracic cord.

We have been able to narrow down these regions from our similar though more extensive material. We find that the fibres for vasomotor control and for sudomotor control are essentially within the same area; that is in the medial part of the equatorial plane, extending from the base of the posterior horn and the lateral horn across the medial half of the white matter of the lateral column. The area that was worked out for the vasomotor pathway was more extensive than that for the sudomotor pathway and the two areas were not exactly the same. These differences might be eliminated if more material were available from which to draw conclusions; they are unlikely to be real.

The location of the descending sympathomotor pathway in the cervical cord, presented in our previous paper, ${ }^{1}$ is close to the posterior angle of the anterior horn, in the medial third of the white matter. In the thoracic cord, this part of the gray matter becomes the lateral horn. It is apparent that this pathway maintains this position throughout the spinal cord down to the $\mathrm{L} 2$ segment. This is the same region in which the fibres for the automatic, unconscious control of micturition and defaecation lie. ${ }^{1617}$

Illert et $a l^{9}$ located the descending fibres in the cat that cause inhibition of sympathetic activity mainly in the region between the dentate ligament and the midline; this is the same region as where we have concluded that the fibres must lie in man. It might be anticipated that fibres for excitation and inhibition of local sympathetic neurons would be the same region.

Kerr and Alexander ${ }^{8}$ found in the cat and monkey that the main vasomotor pathway was in the periphery of the lateral column of the cord. The same location was found in the cat by Foreman and Wurster ${ }^{10}$ and in the dog by Barman and Wurster. ${ }^{11}$ We have several cases in which there were bilateral lesions in this region with no disturbance of vasomotor control.

Kerr and Alexander also obtained slight vasopressor effects from stimulating within the

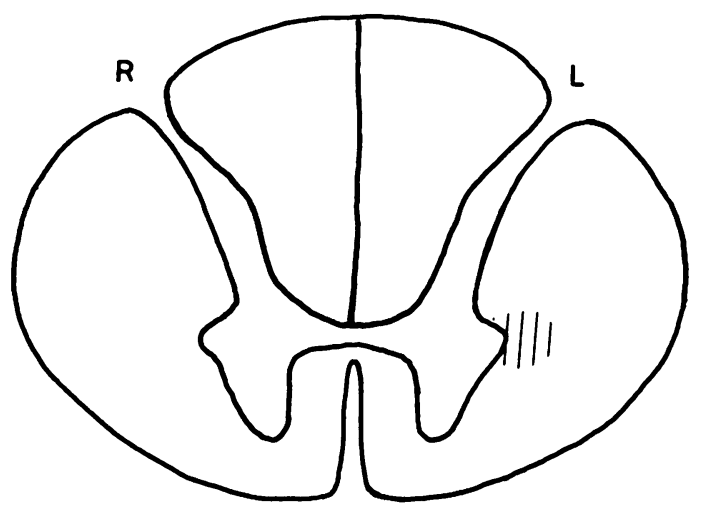

Fig.10 Diagram showing location of descending fibres for sudomotor control. 

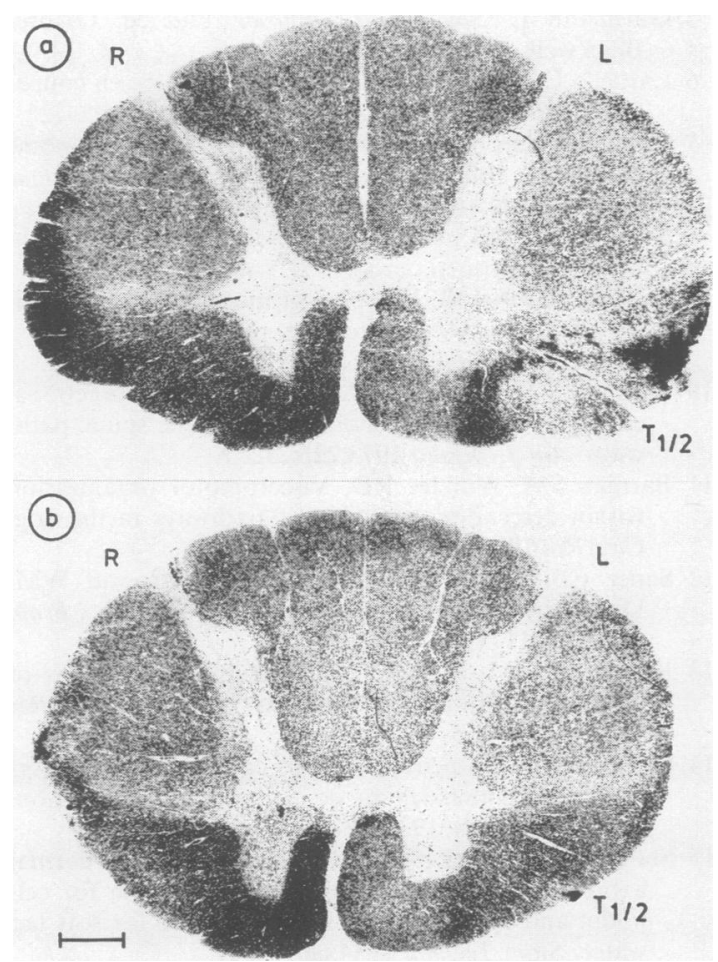

Fig 11 Partial disturbance of sweating. Case 21. Left lesion shown more clearly in upper section, right lesion in lower section. Marchi preparations. Bar $=1 \mathrm{~mm}$.

corticospinal tract. It is possible that the region that they were stimulating included the region lateral to the lateral horn.

The area within which fibres from the hypothalamus to the thoracic gray matter run shown by Saper et $a^{12}$ in the monkey, overlaps with the location that we have found in man, though the greater part of the area within which they located the fibres was further posterior.

The descending pathway to the neurons supplying the orbit and the sweat glands of the head and neck is unilateral; this was shown in our previous paper. ${ }^{1}$ The sympathomotor neurons caudal to those for the head and neck are supplied from both sides of the cord: a lesion of one half of the cord does not remove sympathetic activity. Guttmann ${ }^{5}$ also noted that a unilateral cordotomy did not upset sweating. We conclude that crossing of sympathomotor fibres or relevant commissural fibres starts at the Th 1 segment.

Our evidence suggests that sympathetic fibres for vasomotor control leave the cord cranial to the Th 7 segment. Guttmann ${ }^{18}$ found in patients with traumatic spinal injuries that those with lesions below
Th 5 did not show a profound fall in blood pressure on being placed in the upright posture whereas those with lesions cranial to this level did. The crucial level for vasomotor control is about the same in his total cord transections and in our cordotomies. As preganglionic neurons synapse with postganglionic neurons in ganglia situated at various levels of the chain, any correlation between segmental level of spinal lesion and absence of sympathetic activity is bound to show variations from case to case. This is evident in the literature: what is surprising is that it is not greater.

A practical conclusion from these observations is that this region of the white matter near the lateral horn should be spared in the operation of anterolateral cordotomy. This is to avoid vasomotor paresis and to ensure that the patient can maintain normal temperature regulation. When the operation is carried out in the cervical cord, this region should be spared so as to avoid causing a Horner's syndrome.

The patients presented here were almost all suffering from terminal malignant disease; and therefore examination of sexual function was not applicable. The observations made by one of our younger patients, however, are interesting. He reported that after the operation he was unable to have emissions, though he could still get erections from both manual stimulation and from inducing imagery. However, he no longer had the pleasurable sensations. From this one case, of which the bilateral lesions are shown in fig 11 , it is concluded that the pathways to the sacral parasympathetic neurons were intact; but that those needed to coordinate the total reflex emission had been divided; and that the afferent fibres within the spinothalamic tract essential for conducting impulses subserving the relevant sensation had been divided.

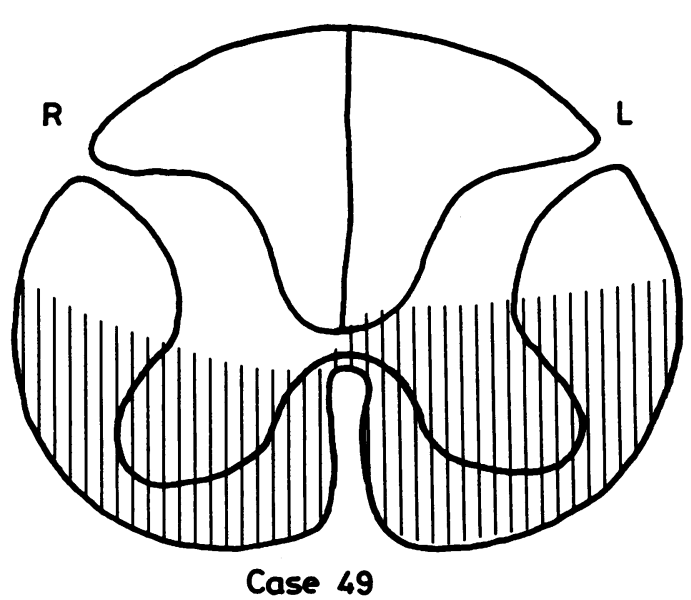

Fig 12 Sweating present in lower limbs. Diagram shows lesions in L 1-2 segments. Case 49. 
Although this is only one case, it is mentioned as the amount of this human material is undoubtedly very small.

This paper completes our series on the location of descending autonomic pathways within the spinal cord.

We are grateful to Sir Wylie McKissock who operated upon the majority of the patients and to all the neurosurgeons and ncuropathologists who provided us with this material. We also record our appreciation to the technicians who prepared the sections and photographs, in particular Miss Patricia Deacon, Miss Ursula Starega and $\mathrm{Mr}$ W Bessant. Our thanks are also due to Dr JT Hughes who has given us the opportunity to complete this work in his laboratory. This work was mainly done when the authors were members of the External Scientific Staff, Medical Research Council.

\section{References}

1 Nathan PW, Smith MC. The location of descending fibres to sympathetic neurons suppling the eye and sudomotor neurons supplying the head and neck. J Neurol Neurosurg Psychiatry 1986;49:187-94.

2 Olszewski J, Baxter D. Cytoarchitecture of the Human Brain. 2nd ed. Basel: Karger, 1982.

3 Foerster O. Operative-experimentelle Erfahrungen beim Menschen über den Einfluss des Nervensystems auf dem Kreislauf. Zeitschr ges Neurol Psychiat 1939;167: 439-61.

4 Foerster O, Gagel O, Mahoney W. Die encephalen Tumoren des Verlängerten Markes, der Brücke und des Mittelhirns. Arch Psychiat Nervenkrank 1939; 110:1-74.
5 Guttmann L. Spinal Cord Injuries. 2nd ed. Oxford: Blackwell, 1976:290-304.

6 Laruelle L. La structure de la moelle épinière en coupes longitudinales. Rev Neurol (Paris) 1937;67:695-725.

7 Laruelle L. Les bases anatomiques du système autonome cortical et bulbo-spinal. III Congrès neurologique international. 46-67. Einar Munksgaard.

8 Kerr FWL. Alexander S. Descending autonomic pathways in the spinal cord. Arch Neurol 1974;10:249-61.

9 Illert M, Gabriel M. Mapping of the spinal cat for sympathetic and blood pressure responses. Brain Res 1970;23:274-6.

10 Foreman RD, Wurster RD. Localisation and functional characteristics of descending sympathetic spinal pathways. Am J Physiol 1973;225:212-7.

11 Barman SM, Wurster RD. Visceromotor organization within descending sympathetic pathways in the dog. Circ Res 1975;37:209-14.

12 Saper CB, Loewy AD, Swanson LW, Cowan WM. Direct hypothalamo-autonomic connections. Brain Res 1976;117:305-12.

13 Kuypers HGM, Maisky VA. Funicular trajectories of descending brain stem pathways in cat. Brain Res 1977;136:159-65.

14 Guttmann L. Ein neues einfaches colorimetrisches; Verfahren zur Untersuchung der Schweissdrüsenfunction. Klin Wochenschr 1937;35:212-4.

15 Starega U. A silver impregnation technique for normal axons in the human central nervous system for celloidin and epon sections, with substitute for soft tap water. Stain Technol 1984;60:103-9.

16 Nathan PW, Smith MC. Spinal pathways subserving defaecation and sensation from the bowel. $J$ Neurol Neurosurg Psychiatry 1953;16:245-56.

17 Nathan PW, Smith MC. The centrifugal pathway for micturition within the spinal cord. $J$ Neurol Neurosurg Psychiatry 1958;21:177-89.

18 Guttman L. Dic Schweisssekretion des Menschen in ihre Beziehung zum Nervensystem. Zeitschr ges Neurol Psychiat 1931;135:1-48. 